\title{
ASSESSMENT OF GENETIC DIVERSITY OF BARBERRY GERMPLASM (BERBERIS SPP.) IN CENTRAL REGIONS OF IRAN BY MORPHOLOGICAL MARKERS
}

\author{
Maryam TATARI ${ }^{1}$, , Ayoubali GHASEMI ${ }^{1}$, Hadi ZERAATGAR ${ }^{2}$ \\ ${ }^{1}$ Isfahan Agricultural and Natural Resources Research and Education Center \\ Agricultural Research, Education and Extension organization (AREEO), Isfahan, Iran \\ ${ }^{2}$ South Khorasan Agricultural and Natural Resources Research and Education Center \\ Agricultural Research, Education and Extension organization (AREEO), Birjand, Iran
}

Received: August 2018; Accepted: June 2019

\begin{abstract}
One of the methods for breeding of fruit trees is the identification and selection of superior genotypes in different regions. Owing to climate changes in the recent years and the urgent need to changing the pattern of cultivation, it is essential to use adapted species to climatic conditions. Barberry is one of the plants that have been naturally grown in some areas of Isfahan province. For accessing the promising genotypes of barberry in Isfahan province, this research was carried out in the main areas of barberry growing. For this purpose, some physiological and pomological traits of about 100 barberry genotypes from different regions of Isfahan province were evaluated according to Union for the Protection of New Varieties of Plants descriptor. Evaluated traits were recorded in each year in four stages, including the physiological dormancy of the tree, the flowering, the vegetative growth of the tree as well as the ripening and harvesting time of berry stages from 2014 to 2016. According to the results, seven genotypes were selected, including Dolat Abad, Semirom, Dehaghan, Red leaf, and Evergreen genotypes as well as two wild genotypes. The results showed that the berry length ranged from 1.06 to $9 \mathrm{~mm}$ and the berry width ranged from 0.4 to $5.2 \mathrm{~mm}$. The dried barberry per kilogram of fresh berries was between 200 and $700 \mathrm{~g}$. The leaf length and leaf width of the studied genotypes were in the range 26-81 and 9-26 mm, respectively. The thorn length varied between 9 and $91 \mathrm{~mm}$. The seed length and seed width were recorded in the range $0-4.5$ and 0-2.6 mm, respectively. Dolat Abad and Dehaghan genotypes had the highest berry length and berry width, respectively. The most dried barberry per kilogram of fresh berries belonged to these two genotypes. Evergreen and Red leaf genotypes had the highest leaf length and leaf width, respectively. The highest seed length and seed width were observed in two wild genotypes of collected barberry. The results of correlation analysis of traits showed that tree growth vigor had a significant positive relationship with berry size, thorn length, seed length, and seed width. Berry firmness had negative correlation with berry length and berry width. On the basis of cluster analysis, genotypes were placed in three groups, so that genotypes from Dolat Abad, Semirom, and Dehaghan regions were placed in a same group. Red leaf and Evergreen genotypes with ornamental application were in another group, and two wild genotypes were also placed in the third group. Eventually, Dolat Abad, Semirom, and Dehaghan genotypes were introduced as the promising genotypes because of seedless berry with the highest berry length and berry width and the most dried barberry per kilogram of fresh berries.
\end{abstract}

Keywords: barberry, berry dimensions, grouping, selection, promising genotype, wild genotype

\section{INTRODUCTION}

Barberry (Berberis spp.) has been recognized and used as a medicinal plant in Iran and other ancient civilizations in the world (Heidari et al. 2009). This genus is the largest genus of the Berberidaceae family that is usually diploid $(2 \mathrm{n}=2 \mathrm{x}=28)$ and rarely tetraploid. The genus Berberis has about 450-500 species 
(Simpson 2006) and is distributed in the temperate and subtropical regions of the northern hemisphere and temperate regions of the southern hemisphere (Ahmed et al. 2011). Barberry originates in East Asia and has two diversity centers in Asia (Eurasia) and the other in South America (Alemardan et al. 2013).

Barberry is tolerant to drought and cold conditions and grows well in mountain areas with cold winters (Alemardan et al. 2013). In the most agricultural areas in Iran, water resources are inadequate and soil and water quality is not appropriate, so the most areas that allocated to the cultivation of barberry are not suitable for the cultivation of a wide range of other products. The cultivation of barberry for residents of these areas has many economic benefits compared to many other fruit trees, and the annual income of thousands of people directly or indirectly depends on this yield (Alemardan et al. 2013). Different types of barberry are grown for uses such as medicinal, ornamental, and food. Its fruit is used in the food industry as a natural colorant. Barberry and its main constituent, berberine, have been used in traditional medicine for a long time (Mohammadzadeh et al. 2017).

Identification of different barberry species is difficult because of the high genetic and geographical variations, inter-specific crosses and spontaneous mutations (Rezaei et al. 2011). In the genus Berberis, there is abundant hybridization between species of this shrubby genus. Therefore, finding unmixed species is difficult (Sodagar et al. 2012). Phenotypical traits are the simplest markers that are directly evaluated genetic diversity within or between populations to estimate morphological differences without the need to complex tools (Weising et al. 2005). The study of morphological characteristics and identification, collection and evaluation of germplasm in breeding programs is very important. Germplasm has been collected from some fruit trees in Iran, such as almond (Sorkheh et al. 2009), jujube (Ghazaeian 2015; Zeraatgar 2013; Tatari et al. 2016), and quince (Abdollahi et al. 2013).

The first comprehensive program for identification and collection of barberry native germplasm in Iran was carried out in the southern Khorasan province during 3 years to protect the genetic resources and use in breeding programs. According to this, geographical location and important characteristics of genotypes were recorded based on the descriptor.
Finally, 18 seeded genotypes and 2 seedless genotypes were identified (Zeraatgar 2013). Bottini et al. (2002) conducted some studies on the barberry genus. The result of these studies showed a considerable variation among barberry species. Kim and Jansen (1994) studied morphological and molecular characteristics of more than 40 barberry species. The results of the studies showed that there are several species of barberry in the world. Many of these species are seeded and have no good edible quality, but they are important from the aspect of natural resources. Six species of barberry (Berberis vulgaris L.) were collected from the areas of Sivas province in Turkey. Analyzing of the antioxidant capacity and their fruit biochemical properties showed that these species are a rich source of natural antioxidants (Özgen et al. 2012).

Among the different species of barberry, B. vulgaris has more economic importance (Heidari et al. 2009). Heidari et al. (2009) conducted some studies on the genetic diversity of barberry populations in the Khorasan province and separated different populations by molecular and morphological markers. Jannatizadeh and Khadivi-Khub (2016) evaluated phenotypic variations of 34 individuals of wild barberry (B. integerrima) and detected significant phenotypic diversity between the studied accessions based on morphological traits. In another study, 133 individuals of barberry (B. vulgaris L. var. asperma) from different regions of Khorasan-e-Jonoobi province from the eastern area of Iran were evaluated using 36 morphological and 6 fruit chemical characters (Goodarzi et al. 2018).

In each country, it is important to study the genetic diversity of a plant species for use in breeding, conservation, and preventing genetic erosion (Finetto 2001), so identification of local genotypes to achieve genotypes with desirable characteristics of a fruit, environmental adaptations, and tolerance to biotic and abiotic stresses is very important. The importance of this topic has increased with global warming and reducing rainfall in the recent years, so it is necessary to change the pattern of cultivation and use of drought- and heat-tolerant plants. Iran as well as Isfahan province is one of the primary areas of distribution and diversity of barberry in the world. So far, most studies have been carried out on the medicinal properties of this yield and little information is available on the variation of edible 
barberry and wild species in Isfahan province. Therefore, identification and evaluation of seeded and seedless barberry genotypes in Isfahan province are essential for use in future breeding programs.

\section{MATERIAL AND METHODS}

Collection site. In this research, the superior genotypes of barberry in some regions of Isfahan province, including Semirom, Dolat Abad, Dehaghan, Isfahan city, and some regions in the west of Isfahan province were evaluated from 2014 to 2016 for 3 years. In order to a preliminary study on morphological and pomological traits, about 100 different barberry genotypes were evaluated in the first year and in each region. These evaluations in each region were carried out in four stages, including the physiological dormancy of the tree, the flowering, the vegetative growth of the tree, and the ripening and harvesting time of berry stages. The main scale of selection for genotypes was more production and being seedless in edible genotypes. Selection criteria for ornamental genotypes were their usability as a hedge or fence in urban green space. The result of these evaluations was the selection of seven distinct genotypes. Geographical location of selected genotypes, including latitude, longitude, and altitude was recorded with the GPS device (Table 1).

Evaluated traits. For the 7 collected genotypes, 23 traits, including some vegetative, flower, and berry traits, were recorded based on the Union for the Protection of New Varieties of Plants (UPOV) descriptor during 2015-2016. To measure the dried barberry per kilogram of fresh berry, the berries of each genotype were harvested using scissors and weighed separately and then were placed in the laboratory conditions for a week and weighed again. The weight of dried barberry was calculated per each kilogram of fresh berry. Qualitative traits (14 traits) were also recorded based on the UPOV descriptor. The symbol and measurement unit of recorded traits are presented in Table 2. The suckers of selected genotypes in each area with sanitary and quarantine principles were sent to the Agriculture and Natural Resources Research Center of Southern Khorasan Province (Birjand) for establishment of barberry national collection.

Data analysis. Analysis of variance and mean comparison for quantitative traits was carried out by SAS software (version 9.1) using Duncan's test. Descriptive statistics, simple correlation between traits (using the Pearson method), and cluster analysis (the Ward method based on the squared Euclidean distance) were performed using SPSS software (version 15).

\section{RESULTS AND DISCUSSION}

\section{Descriptive statistics}

In this research, seven barberry genotypes were identified and collected from different regions of Isfahan province, including three edible genotypes from Dolat Abad, Semirom, and Dehaghan areas; two ornamental genotypes from Isfahan city; and other genotypes from the west of Isfahan province (Table 1).

The average of traits as well as the range and coefficient of variation of quantitative traits in selected barberry genotypes is presented in Table 3. The greatest relative differences between maximum and minimum values were obtained for dried barberry per kilogram of fresh berries, thorn length, and leaf length, which were not according to the results reported by Jannatizadeh and Khadivi-Khub (2016). They only evaluated wild genotypes.

Table 1. Characteristics of collection sites of barberry genotypes

\begin{tabular}{llccc}
\hline \multicolumn{1}{c}{ Barberry type } & \multicolumn{1}{c}{ Collection site } & Latitude & Longitude & Altitude (m) \\
\hline Edible 1 & Dolat Abad & $3248^{\prime} 39.9^{\prime \prime} \mathrm{N}$ & $5140^{\prime} 44^{\prime \prime} \mathrm{E}$ & 1583 \\
Edible 2 & Semirom & $3136^{\prime} 44.3^{\prime \prime} \mathrm{N}$ & $5133^{\prime} 15.9^{\prime \prime} \mathrm{E}$ & 2464 \\
Edible 3 & Dehaghan & $3207^{\prime} 55.4^{\prime \prime} \mathrm{N}$ & $5138^{\prime} 56.3^{\prime \prime} \mathrm{E}$ & 1819 \\
Red leaf & The flower garden of Isfahan & $3228^{\prime} 22.8^{\prime \prime} \mathrm{N}$ & $5141^{\prime} 53.5^{\prime \prime} \mathrm{E}$ & 1599 \\
Evergreen & The flower garden of Isfahan & $3228^{\prime} 22.8^{\prime \prime} \mathrm{N}$ & $5141^{\prime} 53.5^{\prime \prime} \mathrm{E}$ & 1599 \\
Zarafshani (wild) & West of province & $3236^{\prime} 56.6^{\prime \prime} \mathrm{N}$ & $5127^{\prime} 56.6^{\prime \prime} \mathrm{E}$ & 1631 \\
Broadleaf (wild) & West of province & $32366^{\prime} 56.6^{\prime \prime} \mathrm{N}$ & $5127^{\prime} 56.6^{\prime \prime} \mathrm{E}$ & 1631 \\
\hline
\end{tabular}


Table 2. Symbol and measurement method of recorded traits based on UPOV descriptor

\begin{tabular}{|c|c|c|c|}
\hline Characteristic & Symbol & $\begin{array}{c}\text { Unit } \\
\text { of measurement }\end{array}$ & Measurement method \\
\hline Tree vigor & $\mathrm{TV}$ & Code & $\begin{array}{l}\text { extremely weak (1), weak (3), intermediate (5), } \\
\text { vigorous ( } 7) \text {, extremely vigorous (9) }\end{array}$ \\
\hline Tree growth habit & TGH & Code & $\begin{array}{l}\text { extremely upright (1), upright (3), semi spreading (5), } \\
\text { spreading (7), drooping (9) }\end{array}$ \\
\hline Being Deciduous & $\mathrm{BD}$ & Code & deciduous (1), evergreen (3) \\
\hline Leaf length & LL & $\mathrm{mm}$ & ruler (average of 10 leaves) \\
\hline Leaf width & LW & $\mathrm{mm}$ & ruler (average of 10 leaves) \\
\hline Leaf shape & LS & Code & narrow (1), oval (3), cordate (5), ovate (7), oblong (9) \\
\hline Thorn length & $\mathrm{TL}$ & $\mathrm{mm}$ & ruler (mean of 10 thorn) \\
\hline Place of flower bud formation & PFBF & Code & spur (1), one-year old branch, (3), both (5) \\
\hline Flower color & $\mathrm{FC}$ & Code & light yellow (1), yellow (3), orange (5), pink (7) \\
\hline Flower size & FLS & Code & small (1), medium (3), large (5) \\
\hline Fruiting in isolation conditions & FIC & Code & low (1), intermediate (3), high (5) \\
\hline Berry shape & BS & Code & cylindrical (1), globose (3), semi-globose (5) \\
\hline Color of ripening berry & $\mathrm{CRB}$ & Code & pink (1), light red (3), dark red (5), dark blue (7) \\
\hline Wax on berry & WB & Code & yes (1), no (3) \\
\hline Berry length & BL & $\mathrm{mm}$ & caliper (average of 10 berries) \\
\hline Berry width & BW & $\mathrm{mm}$ & caliper (average of 10 berries) \\
\hline Berry size & BRS & Code & small (1), medium (3), large (5) \\
\hline Peduncle length & PL & $\mathrm{mm}$ & ruler (mean of 10 berries) \\
\hline $\begin{array}{l}\text { Dried barberry per kilogram } \\
\text { of fresh berry }\end{array}$ & DPB & $\mathrm{gr}$ & digital scale \\
\hline Firmness & $\mathrm{F}$ & Code & soft (1), intermediate (3), firm (5) \\
\hline Rate of juice & RJ & Code & juicy (1), fleshy and low juicy (3), low juicy (5) \\
\hline Seed length & SL & $\mathrm{mm}$ & caliper (mean of 10 seeds) \\
\hline Seed width & SW & $\mathrm{mm}$ & caliper (mean of 10 seeds) \\
\hline
\end{tabular}

Table 3. Mean, range and coefficient of variation in studied traits

\begin{tabular}{lccccc}
\hline \multicolumn{1}{c}{ Characteristics } & CV (\%) & Standard deviation & Minimum & Mean & Maximum \\
\hline Leaf length (LL) & 38.61 & 18.15 & 26 & 47 & 81 \\
Leaf width (LW) & 34.49 & 5.96 & 9 & 17.28 & 26 \\
Thorn length (TL) & 90.26 & 30.43 & 9 & 33.71 & 91 \\
Berry length (BL) & 54.91 & 3.41 & 1.1 & 6.21 & 9 \\
Berry width (BW) & 59.53 & 2.03 & 0.4 & 3.41 & 5.2 \\
Peduncle length (PL) & 75.67 & 1.68 & 0.7 & 2.22 & 4.4 \\
Dried barberry per kilogram of fresh berry (DPB) & 23.43 & 127.24 & 400 & 542.85 & 700 \\
Seed length (SL) & 91.79 & 1.23 & 0 & 1.34 & 4.5 \\
Seed width (SW) & 94.36 & 0.67 & 0 & 0.71 & 2.6 \\
\hline
\end{tabular}


The coefficient of variation varied from 23.43 to $94.36 \%$. The thorn length and the length and width of berries and seeds as well as the peduncle length traits had the coefficient of variation of more than $50 \%$. The traits with higher coefficient of variation are more distinct between individuals and are reliable markers for studying individuals (Khadivi-Khub \& Etemadi-Khah 2015). High variation in tree growth habit and berry shape traits was reported by Ahmed et al. (2013) who evaluated 30 barberry genotypes from Pakistani regions. Similarly, Rezaei (2009) reported a high variation among Iranian barberry genotypes. He observed more variation in the number of berries in 1-yearold branch, berry anthocyanin, and fresh weight traits. However, in another study, variation in the Iranian population of seedless barberry was reported as about zero (Heidari et al. 2009).

\section{Mean comparison}

The analysis of variance showed that the evaluated genotypes had significant differences in more studied traits, which is due to diversity in the studied traits, so it is possible to select a genotype for different values of a trait (Table 4). The length and width of a leaf were $26-81$ and 9-26 mm, respectively. The Zarafshani genotype had the lowest leaf dimensions. The highest leaf length belonged to the Evergreen genotype, and the highest leaf width was related to the Red leaf genotype. It seems that genotypes with lower leaf dimensions had lengthier thorns. Ahmed et al. (2013) reported the leaf length and leaf width in their investigated barberry ranged from 96.9 to $66.7 \mathrm{~mm}$ and 33.1 to $25.8 \mathrm{~mm}$, respectively. The range of leaf length and leaf width in barberry genotypes studied by them was more than the values reported in the present study. Genetic and environmental factors are responsible for leaf size variation (Ahmed et al. 2013).

The length and width of the berries in the studied barberry were in the range 1.06-9 and 0.4$5.2 \mathrm{~mm}$, respectively. In another study, the berry length varied from 9.75 to $7.12 \mathrm{~mm}$, and the berry width was in the range 4.34-2.65 mm (Ahmed et al. 2013). Goodarzi et al. (2018) also investigated on the barberry genotypes in Khorasan-e-Jonoobi and reported that the berry length and berry width were in the range of 7.4-10.84 and $4.39-8.05 \mathrm{~mm}$, respectively, which was more than the means of the berry length and berry width in this research. Ornamental genotypes had the least berry dimensions. Lower berry length and berry width of the ornamental genotypes, including Red leaf and Evergreen, is the main cause of this difference. Naturally, the dried barberry per kilogram of fresh berries of the Red leaf and Evergreen ornamental genotypes that had lower berry dimensions was lesser than that of other genotypes. Peduncle length was higher in genotypes with more seed dimensions.

Qualitative traits of selected genotypes were presented in Table 5. The tree growth habit of the studied genotypes was similar to that of 30 genotypes evaluated by Ahmed et al. (2013), who reported the right, spreading and semi-spreading growth habit. The range of berry color among the studied genotypes in this research was less than that of barberry genotypes examined by Ahmed et al. (2013). They reported purple, blue, and violet colors for their genotypes. Rezaei et al. (2011) reported that the seedless genotypes collected from different regions of Khorassan were red while the seeded genotypes had various colors including dark blue, red, light red, and reddish-dark. This color variation was not observed in the seeded genotypes of the present research.

Although diversity evaluation is not reliable only based on morphological traits, but some traits in this research, such as leaf dimensions; length of berries, seeds, and thorns; and leaf shape, can be used as morphological markers for the identification of barberry. Lacombe et al. (2003) used morphological markers to study the genetic diversity of wild grapes and compare their variation with other cultivars. Morphological data analysis did not show any difference between wild grapes of different geographic regions (Lacombe et al. 2003), whereas in the present study, two wild genotypes showed differences with each other in thorn length, tree growth habit, leaf shape, flower size, and color of ripening berry traits.

\section{Correlation of traits}

The results of correlation among traits showed that there is a significant correlation between some of the measured traits (Table 6). A high correlation can 
be used to estimate other traits. There was a significant positive correlation between tree growth vigor with berry size and seed length and seed width. This correlation is reasonable because, with increasing tree growth vigor and increasing foliage, photosynthesis increases and sufficient carbohydrates are provided to produce flower bud and thus increase the berry size. This process will continue until the shadow of the tree leads to reduce photosynthesis and carbohydrate production (Talaei 1999).
Trees with more thorn length had more seed length and seed width. Similarly, a correlation between thorn length and seed dimensions has also been reported in the jujube (Tatari et al. 2016). Jannatizadeh and Khadivi-Khub (2016) reported a positive correlation between the length and width of the berries and seeds, whereas this correlation was not observed in the present study. Berries with more peduncle length had more seed length and seed width.

Table 4. Mean of quantitative traits for seven barberry genotypes

\begin{tabular}{llllllllll}
\hline \multicolumn{1}{c}{ Barberry type } & LL & LW & TL & BL & BW & PL & DPB & SL & SW \\
Dolat Abad & $53 \mathrm{~b}$ & $19 \mathrm{ab}$ & $20 \mathrm{c}$ & $9 \mathrm{a}$ & $5 \mathrm{ab}$ & $0.9 \mathrm{~b}$ & $700 \mathrm{a}$ & $0 \mathrm{~b}$ & $0 \mathrm{~b}$ \\
Semirom & $40 \mathrm{c}$ & $21 \mathrm{ab}$ & $15 \mathrm{~cd}$ & $7.6 \mathrm{a}$ & $4.5 \mathrm{ab}$ & $3.5 \mathrm{a}$ & $600 \mathrm{~b}$ & $0 \mathrm{~b}$ & $0 \mathrm{~b}$ \\
Dehaghan & $53 \mathrm{~b}$ & $20 \mathrm{ab}$ & $22 \mathrm{c}$ & $8.6 \mathrm{a}$ & $5.2 \mathrm{a}$ & $0.8 \mathrm{~b}$ & $700 \mathrm{a}$ & $0 \mathrm{~b}$ & $0 \mathrm{~b}$ \\
Red leaf & $45 \mathrm{bc}$ & $26 \mathrm{a}$ & $9 \mathrm{~d}$ & $1.06 \mathrm{~b}$ & $0.4 \mathrm{c}$ & $0.7 \mathrm{~b}$ & $200 \mathrm{c}$ & $0.5 \mathrm{~b}$ & $0.1 \mathrm{~b}$ \\
Evergreen & $81 \mathrm{a}$ & $15 \mathrm{bc}$ & $18 \mathrm{~cd}$ & $1.4 \mathrm{~b}$ & $0.7 \mathrm{c}$ & $1.2 \mathrm{~b}$ & $200 \mathrm{c}$ & $0 \mathrm{~b}$ & $0 \mathrm{~b}$ \\
Zarafshani & $26 \mathrm{~d}$ & $9 \mathrm{c}$ & $91 \mathrm{a}$ & $7.6 \mathrm{a}$ & $4.4 \mathrm{ab}$ & $4.1 \mathrm{a}$ & $500 \mathrm{~d}$ & $4.5 \mathrm{a}$ & $2.6 \mathrm{a}$ \\
Broadleaf & $31 \mathrm{~d}$ & $11 \mathrm{c}$ & $61 \mathrm{~b}$ & $8.2 \mathrm{a}$ & $3.5 \mathrm{~b}$ & $4.4 \mathrm{a}$ & $500 \mathrm{~d}$ & $4.4 \mathrm{a}$ & $2.3 \mathrm{a}$ \\
\hline
\end{tabular}

Means in each column followed by the same letter do not differ significantly at $5 \%$ level of Duncan's multiple range test

Table 5. Qualitative traits for seven barberry genotypes

\begin{tabular}{lccccccc}
\hline Barberry type & TV & TGH & BD & LS & PFBF & FC & FLS \\
\hline Dolat Abad & vigorous & extremely upright & deciduous & oblong & both & yellow & small \\
\hline Semirom & vigorous & upright & deciduous & oblong & both & yellow & small \\
\hline Dehaghan & vigorous & upright & deciduous & cordate & both & yellow & small \\
\hline Red leaf & vigorous & extremely upright & deciduous & cordate & 1-year-old branch & yellow & small \\
\hline Evergreen & vigorous & upright & ever green & narrow & 1-year-old branch & yellow & small \\
\hline Zarafshani & extremely vigorous & upright & deciduous & ovate & both & yellow & small \\
\hline Broadleaf & extremely vigorous & \multirow{2}{*}{ semi spreading } & deciduous & oblong & both & yellow & medium \\
\hline
\end{tabular}

Continuous table 5. Qualitative traits for seven barberry genotypes

\begin{tabular}{lccccccc}
\hline Barberry type & FIC & BS & CRB & WB & BRS & F & RJ \\
\hline Dolat Abad & intermediate & globose & light red & yes & medium & soft & juicy \\
\hline Semirom & high & globose & light red & yes & medium & soft & juicy \\
\hline Dehaghan & high & cylindrical & light red & yes & medium & soft & fleshy and low juicy \\
\hline Red leaf & low & cylindrical & light red & yes & small & firm & fleshy and low juicy \\
\hline Evergreen & intermediate & cylindrical & light red & yes & small & firm & low juicy \\
\hline Zarafshani & intermediate & cylindrical & dark red & no & medium & soft & low juicy \\
\hline Broadleaf & intermediate & cylindrical & light red & no & medium & soft & \\
\hline
\end{tabular}




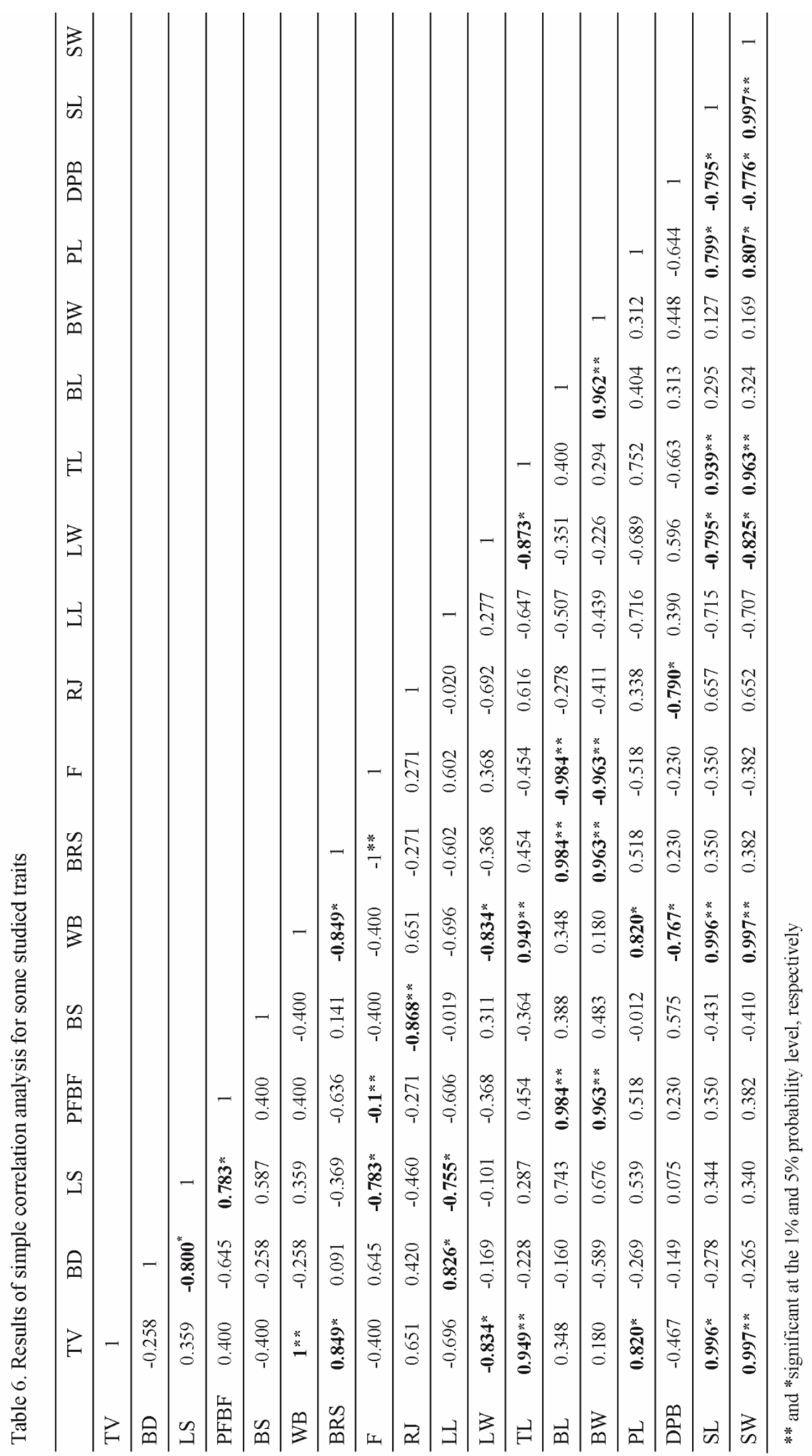


In general, it can be said that nonedible barberry genotypes, which is seeded, have more thorn length and seed dimensions. It seems that these genotypes are evolutionary behind the domestic and edible genotypes. According to Moosazadeh et al. (2015), if there is a positive correlation between two traits in a plant, the breeding program is easier to perform. Accordingly, in breeding programs, correlations among vegetative and reproductive traits can be used and early selection of seedlings before the reproductive phase can be carried out.

\section{Cluster analysis}

Using cluster analysis, genotypes were classified into five groups at five squared Euclidean distance based on the Ward method (Fig. 1). In the first group, Dolat Abad, Isfahan, Semirom, and Dehaghan genotypes were placed. These genotypes are edible and had the highest berry length and berry width, as well as the highest dried barberry per kilogram of fresh berries. The berries of these genotypes were seedless, semiglobose, and juicy. Being deciduous, the vigorous growth of trees, the formation of flower bud on both 1-year-old branch and spur, being the wax on the berry, and large-sized berry with soft tissue were other characteristics of this group. These three genotypes were located in the same group despite being in different locations. The cause can be attributed to their similar origin or to the morphological changes of seedlings after transplantation and cultivation in new conditions (Khakdaman et al. 2007).

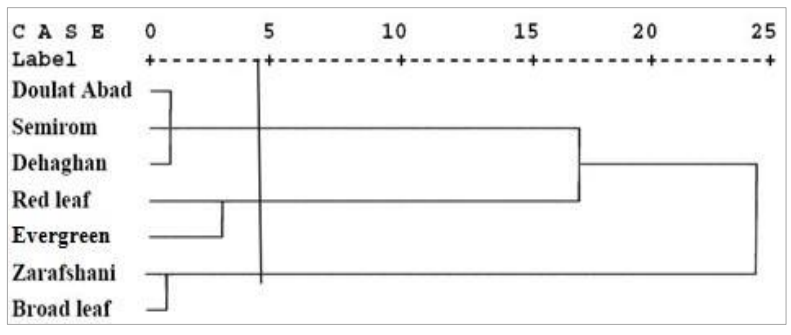

Fig. 1. Grouping of 7 barberry genotypes based on measured characteristics by Ward method

The Red leaf and Evergreen genotypes placed in the second group have ornamental application. In these genotypes, flower buds were formed on 1-yearold branches. Their berries had the lowest length and width and were also firm, fleshy, and low juicy. The least thorn length, the vigorous growth of the tree, the lowest dried barberry per kilogram of fresh berries, seedless, light red and cylindrical berry, being the wax on the berry, and small size of berry were the characteristics of the genotypes in this group.

Two wild genotypes were placed in the third group. The berries of this group had the least leaf length and width. The highest thorn and peduncle length, large berry, being deciduous, the formation of flower bud on both 1-year-old branch and spur, and globose berry were the characteristics of the genotypes in this group. The berries of these two genotypes were seeded and had the highest seed dimensions. The tree vigor in these two genotypes was more than that in other genotypes. Their berries were low juicy, and there was no wax on the berry.

In the identification of barberry germplasm in Southern Khorasan province, 20 different barberry genotypes were identified, of these 18 genotypes were placed in the seeded group and 2 genotypes were seedless (Zeraatgar 2013). Using cluster analysis, 17 strawberry cultivars were distinguished based on 14 morphological traits (Nielsen \& Lovell 2000). Barberry genotypes of Khorasan were also divided into four main groups (Rezaei et al. 2011). Although the seedless cultivars were not placed in a separate group, but similar to the present study, they were placed in a separate subgroup. Regner et al. (2004) did not observe a close relationship between wild and edible grape cultivars and genotypes. In the present study, there was no relationship between the edible and wild barberry genotypes.

Heidari et al. (2009) reported that B. integerrima is a dominant species in the west of Iran. The results of morphological studies by Rezaei et al. (2011) showed that B. vulgaris is very similar to B. integerrima. Jafari \& Gharaghani (2012) observed the species that have the most relationship and the genotypes that were placed in a similar species show the most similarity in the results of cluster analysis.

The results indicated a high morphological diversity of studied genotypes of barberry. Seed propagation and natural hybridization are the main reasons for this variation (Jannatizadeh \& Khadivi-Khub 2016). Furthermore, this considerable variability may be mainly due to incompatibility. Self-incompatibility is observed in both the seedless cultivars and wild barberry (Alemardan et al. 2013; Ebadi et al. 2010). 


\section{CONCLUSIONS}

Diversity allows us to choose the superior genotypes that adapted for the years in a region. The recognition of vegetative characteristics and the quantitative and qualitative traits of berry provides the possibility to select and improve the genotypes for cultivation. It also helps identify the genotypes to protect them. Considering the studied traits, Dolat Abad, Semirom, and Dehaghan genotypes were more desirable and suitable for the establishment of the orchard. Two Red leaf and Evergreen genotypes are suitable for hedges or fences in urban green spaces. These two genotypes can be used in breeding programs of barberry, because of the production of seedless berry. Two wild species of barberry in Isfahan province are distributed in different regions of west and southwest of Isfahan province and generally in most areas of Zagros. Wild barberries have been exposed to weather changes, disease, and different stresses over time and have been able to create a natural security by compatibility, so these genotypes are likely to have genes related to different stress tolerance that can be used in breeding programs. These genotypes must be conserved as valuable genetic resources.

\section{REFERENCES}

Abdollahi H., Alipour M., Khorramdel Azad M., Ghasemi A., Adli M., Atashkar D. et al. 2013. Establishment and primary evaluation of quince germplasm collection from various regions of Iran. Acta Horticulturae 976: 199-206. DOI: 10.17660/actahortic.2013.976.25.

Ahmed M., Anjum M.A., Shinwari Z.K., Awan M.S., Rabbani M.A. 2011. Assessment of variability in fruit quality parameters of Pyrus germplasm collected from Azad Jammu and Kashmir (Pakistan). Pakistan Journal of Botany 42: 971-981.

Ahmed M., Anjum M.A., Naz R.M.M., Khan M.R., Hussain S. 2013. Characterization of indigenous barberry germplasm in Pakistan: variability in morphological characteristics and nutritional composition. Fruits 68: 409-422. DOI: 10.1051/fruits/2013085.

Alemardan A., Asadi W., Rezaei M., Tabrizi L., Mohammadi S. 2013. Cultivation of Iranian seedless barberry (Berberis integerrima 'Bidaneh'): A medicinal shrub. Industrial Crops and Products 50: 276-287. DOI: 10.1016/j.indcrop.2013.07.061.

Bottini M.C.J., De Bustos A., Jouve N., Poggio L. 2002. AFLP characterization of natural populations of Berberis (Berberidaceae) in Patagonia, Argentina. Plant Systematics and Evolution 231: 133-142. DOI: $10.1007 / \mathrm{s} 006060200015$.

Ebadi A., Rezaei M., Fatahi R. 2010. Mechanism of seedlessness in Iranian seedless barberry (Berberis vulgaris L. var. asperma). Scientia Horticulturae 125: 486-493. DOI: 10.1016/j.scienta.2010.04.002.

Finetto G.A. 2001. The importance of germplasm preservation and use for temperate zone fruit production in the tropics and subtropics. Acta Horticulturae 565: 25-32. DOI: 10.17660/actahortic.2001.565.2.

Ghazaeian M. 2015. Genetic diversity of jujube (Ziziphus jujuba Mill.) germplasm based on vegetative and fruits physicochemical characteristics from Golestan province of Iran. Comunicata Scientiae 6: 10 16. DOI: $10.14295 /$ cs.v6i1.597.

Goodarzi H., Khadivi A., Abbasifar A., Akramian M. 2018. Phenotypic, pomological and chemical variations of the seedless barberry (Berberis vulgaris $\mathrm{L}$. var. asperma). Scientia Horticulturae 238: 38-50. DOI: 10.1016/j.scienta.2018.04.040.

Heidari S., Marashi H., Farsi M., Mirshamsi-Kakhki A. 2009. Assessment of variation in wild and cultivated Berberis populations of Khorasan provinces using morphological markers and comparing to data resulted from AFLP markers. Iranian Journal of Field Crops Research 7: 401-410. [in Persian]

Jafari Z., Gharaghani A. 2012. Study of growth and yield of some blackberries species from throughout Iran in Bajgah. Msc. thesis. Department of Horticulture, University of Shiraz, Iran. [in Persian]

Jannatizadeh A., Khadivi-Khub A. 2016. Morphological variability of Berberis integerrima from Iran. Erwerbs-Obstbau 58: 247-252. DOI: 10.1007/s10341-016-0285-7.

Khadivi-Khub A., Etemadi-Khah A. 2015. Phenotypic diversity and relationships between morphological traits in selected almond (Prunus amygdalus) germplasm. Agroforestry Systems 89: 205-216. DOI: $10.1007 / \mathrm{s} 10457-014-9754-x$.

Khakdaman H., Pourmeidani A., Adnani S.M. 2007. Study of genetic variation in Iranian jujube (Ziziphus jujuba Mill.) ecotypes. Iranian Journal of Rangelands and Forest Plants Breeding and Genetic Research 14: 202-214. [in Persian] 
Kim Y.-D., Jansen R.K. 1994. Characterization and phylogenic distribution of a chloroplast DNA rearrangement in the Berberidaceae. Plant Systematics and Evolution 193: 107-114. DOI: 10.1007/bf00983544.

Lacombe T., Laucou V., Di Vecchi M., Bordenave L., Bourse T., Siret R. et al. 2003. Inventory and characterization of Vitis vinifera ssp. sylvestris in France. Acta Horticulturae 603: 553-559. DOI: 10.17660/actahortic.2003.603.73.

Mohammadzadeh N., Mehri S., Hosseinzadeh H. 2017. Berberis vulgaris and its constituent berberine as antidotes and protective agents against natural or chemical toxicities. Iranian Journal of Basic Medical Sciences 20: 538-551. DOI: 10.22038/ijbms.2017.8678.

Moosazadeh R., Shoor M., Tehranifar A., Davarynejad Gh.H., Mokhtaryan A. 2015. Evaluation of genetic diversity in some grape cultivars using fruit qualitative and quantitative characteristics. Journal of Crop Production and Processing 21: 179-192. DOI: 10.18869/acadpub.jcpp.5.17.335. [in Persian]

Nielsen J.A., Lovell P.H. 2000. Value of morphological characters for cultivar identification in strawberry (Fragaria $\times$ ananassa). New Zealand Journal of Crop and Horticultural Science 28: 89-96. DOI: 10.1080/01140671.2000.9514128.

Özgen M., Saraçoğlu O., Geçer E.N. 2012. Antioxidant capacity and chemical properties of selected barberry (Berberis vulgaris L.) fruits. Horticulture, Environment, and Biotechnology 53: 447-451. DOI: 10.1007/s13580-012-0711-1.

Regner F., Hack R., Gangl H., Leitner G., Mandl K., Tiefenbrunner W. 2004. Genetic variability and incidence of systemic diseases in wild vines (Vitis vinifera ssp. silvestris) along the Danube. Vitis 43: 123-130.

Rezaei M. 2009. Evaluation of barberry genotypes diversity using genetic marker and study seedlessness mechanism in seedless barberry. $\mathrm{PhD}$ thesis, Department of Horticultural Sciences, University of Tehran, Karaj, Iran. [In Persian]

Rezaei M., Ebadi A., Reim S., Fatahi R., Balandary A., Farrokhi N., Hanke M.V. 2011. Molecular analysis of Iranian seedless barberries via SSR. Scientia Horticulturae 129: 702-709. DOI: 10.1016/j.scienta.2011.05.021.

Simpson M.G. 2006. Plant Systematics. Elsevier Academic Press, Amsterdam, Netherlands, 590 p.

Sodagar N., Bahrami A.R., Memariani F., Ejtehadi H., Vaezi J., Khosravi A.R. 2012. Biosystematic study of the genus Berberis L. (Berberidaceae) in Khorassan, NE Iran. Plant Systematics and Evolution 298: 193-203. DOI: 10.1007/s00606-011-0537-9.

Sorkheh K., Shiran B., Rouhi V., Asadi E., Jahanbazi H., Moradi H. et al. 2009. Phenotypic diversity within native Iranian almond (Prunus spp.) species and their breeding potential. Genetic Resources and Crop Evolution 56: 947-961. DOI: 10.1007/s10722-009-9413-7.

Talaei A. 1999. Physiology of temperate zone fruit trees. University of Tehran Printing and Publishing Institute, Iran, 423 p. [in Persian]

Tatari M., Ghasemi A., Mousavi A. 2016. Genetic diversity of Jujube germplasm (Ziziphus jujuba Mill.) based on morphological and pomological traits in Isfahan province, Iran. Crop Breeding Journal 4-6: 79-85. DOI: 10.22092/cbj.2016.107110.

Weising K., Nybom H., Wolff K., Kahl G. 2005. DNA Fingerprinting in Plants. Principle, Methods, and Applications, $2^{\text {nd }}$ ed. CRC Press, USA, $472 \mathrm{p}$.

Zeraatgar H. 2013. Study on genetic diversity of barberry germplasm in South Khorasan and creation of collection orchard. $7^{\text {th }}$ Iranian Horticultural Science Congress, 23-26 September, Isfahan, Iran. [in Persian] 